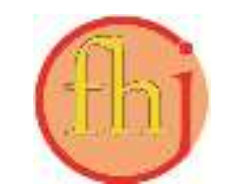

Faletehan Health Journal, 8 (1) (2021) 65-70

www. journal.Ippm-stikesfa.ac.id/ojs/index.php/FHJ

ISSN 2088-673X | e-ISSN 2597-8667

\title{
Efektifitas Terapi Oksigen Terhadap Downes Score pada Pasien Asfiksia Neonatus di Ruang Perinatologi
}

\author{
Nurviyanti ${ }^{1}$, Sri Suparti ${ }^{1^{*}}$ \\ ${ }^{1}$ Universitas Muhammadiyah Purwokerto \\ *Corresponding Author: srisuparti@ump.ac.id
}

\begin{abstract}
Abstrak
Asfiksia merupakan resiko tinggi pada bayi baru lahir yang dapat menyebabkan kematian atau sakit berat. Bayi asfiksia dikelola dengan terapi oksigen untuk menghindari distress pernapasan. Analisis derajat distres pernapasan dapat menggunakan Downes score. Dikatakan baik bila jumlah nilai Downes score semakin kecil atau nol. Tujuan penelitian ini untuk mengetahui efektifitas terapi oksigen terhadap Downes score pada pasien asfiksia neonatus. Jenis penelitian kuantitatif dengan observasi analitik dan pendekatan prospektif. Jumlah sampel sebanyak 25 responden dengan teknik accidental sampling. Instrumen penelitian yang digunakan adalah lembar observasi Downes score. Data dikumpulkan dari bayi asfiksia sedang hingga berat, dengan menilai Downes score pra dan pasca terapi oksigen dan dianlisis dengan uji Wilcoxon test. Hasil penelitian menunjukkan jenis asfiksia terbanyak adalah asfiksia sedang (88\%) dengan terapi oksigen nasal kanul $64 \%$. Rata rata dan standar deviasi Downe Score pra terapi oksigen adalah 3,20 $\pm 2,041$ dan pasca terapi adalah $1,04 \pm 1,881$. Analisis data menggunakan Uji Wilcoxon menunjukkan nilai $Z$ sebesar $-4,173$ dan nilai significancy sebesar 0,001 $(p<0,05)$, dapat disimpulkan terdapat penurunan Downes score pada bayi asfiksia yang mandapat terapi oksigen.
\end{abstract}

Kata Kunci: Asfiksia, Downes Score, Terapi Oksigen

\section{The Effectiveness of Oxygen Theraphy on Downes Score of Neonatal Asphyxia Patients in Perinatology Room}

\begin{abstract}
Asphyxia is a high risk for newborns since it causes death or serious illness. Newborns with asphyxia are treated with oxygen therapy to avoid respiratory distress. The degree of respiratory distress is analyzed by using Downes score. This research aimed to find out the effectiveness of oxygen therapy on Downes score of neonatal asphyxia patients in perinatology room. It was a descriptive quantitative research with analytical observation and prospective approach. 25 patients as sample were taken by accidental sampling technique. The research instrument used was the Downes score observation sheet. The data were collected from moderate to severe asphyxia infants by assessing the Downes score before and after oxygen therapy and analyzed by Wilcoxon test. The results showed largery type of asphyxia occurred was the moderate one (88\%) and the respondents got nasal oxygen therapy (64\%). The mean score and the standard deviation of the pre-oxygen therapy Downe Score was 3.20 \pm 2.041 and the post-therapy was 1.04 \pm 1.881 . The data analysis by Wilcoxon test showed the Z-score was -4.173 and the significance level was $0.000(p<0.05)$. To conclude, there is a Downes score decrease of asphyxia newborns who get oxygen therapy.

Keywords: Asphyxia, Downes Score, Oxygen Theraphy
\end{abstract}




\section{Pendahuluan}

Penyebab utama kematian neonatal pada minggu pertama (0-6 hari) adalah asfiksia (36\%), prematuritas $(32 \%)$ serta sepsis (12\%) sedangkan bayi usia 7-28 hari adalah sepsis (22\%), kelainan kongenital (19\%) dan pneumonia (17\%). Upaya menurunkan angka kematian bayi akibat bayi berat lahir rendah, infeksi pasca lahir, hipotermia dan asfiksia adalah perawatan antenatal dan pertolongan persalinan sesuai standar yang harus disertai dengan perawatan neonatal yang adekuat (Profil Kesehatan Indonesia, 2016). Asfiksia memberikan kontribusi yang tinggi pada kematian neonatal. Asfiksia adalah suatu keadaan kegawatan bayi berupa kegagalan bernafas secara spontan serta teratur segera setelah lahir (Mochtar, 2013).

Asfiksia neonatrum menyebabkan suplai oksigen ke tubuh menjadi terhambat, jika terlalu lama dapat membuat bayi menjadi koma, walaupun sadar dari koma bayi akan mengalami cacat otak (Indriani et al., 2015), sehingga kegawatan nafas pada neonatus dapat menjadikan henti nafas bahkan kematian, maka dapat mempengaruhi tingkat mordibitas dan mortalitas pada bayi baru lahir (Kosim, 2016). Hasil Penelitian sebelumnya menunjukkan penyebab Respiratory Distress Syndrom (RDS) pada neonatus dari 200 kasus gangguan pernafasan adalah 170 kasus karena masalah pernafasan, 24 karena masalah persarafan dan 6 kasus karena penyebab jantung. Takipnea transien dari bayi baru lahir adalah penyebab paling umum dari gangguan pernapasan bayi cukup bulan sedangkan penyakit membran hialin umum terjadi pada bayi prematur (Brahmaiah \& Reddy, 2017).

Derajat distres napas dapat dinilai dengan menggunakan Downes score, komponen yang terdapat dalam Downes score adalah frekuensi napas, aliran udara pada kedua paru, sianosis, suara grunting dan retraksi. Downes score lebih sederhana dan cepat sebagai penilaian kegawatan nafas untuk pengambilan keputusan tentang perawatan lanjut terhadap neonatal tanpa pengukuraan pulse oximetry atau pemeriksaan analisa gas darah (Buch et al., 2013). Downes score lebih mudah digunakan oleh perawat dibandingkan dengan alat ukur lain seperti Silverman Anderson untuk memprediksi nilai $\mathrm{PCO}_{2}$ pada bayi dengan kegawatan pernafasan (Hedstrom et al., 2018) namun akurasi dan kecepatan Downes score lebih baik (A et al., 2016). Bahkan jika dibandingkan dengan alat ukur baru yang dikembangkan oleh Harada et al., (2019) untuk memprediksi pemenuhan pernafasan yang buruk pada bayi yaitu Visual Function Scale (VFS), Downes Score lebih mudah dan cepat dalam menentukan penanganan pasien. Penilaian keparahan pernafasan dengan Downes score dapat digunakan untuk menentukan pemberian terapi oksigen atau perawatan bayi pada level 1,2 atau 3 (John et al., 2015).

Terapi oksigen yang akan digunakan pada bayi baru lahir dengan asfiksia, $R D S$ dan Meconium Aspiration Syndrom (MAS) antara lain oksigen terapi nasal, Continuous Positive Airway Pressure (CPAP) atau ventilasi mekanik tergantung pada tingkat keparahan gangguan pernafasan bayi yang dilihat dari nilai Downes score (John et al., 2015) termasuk pemberian terapi surfaktan untuk mencegah kematian (Pattar \& Das, 2018). Bahkan Downes score disebutkan mampu memprediksi kematian neonatal secara akurat (John et al., 2015). Penelitian tentang terapi oksigen terhadap nilai Downes score pada bayi asfiksia belum banyak dilakukan di Indonesia. Penting untuk mengetahui keefektifan terapi oksigen terhadap status respirasi bayi mengingat dampak besarnya adalah risiko kematian. Penelitian ini lebih komprehensif dengan mengambil data dari bayi dan ibu yang dapat menggambarakan secara deskriptif karaktersitik responden dan mengetahui efektifitas dari terapi oksigen terhadap nilai Downes score.

\section{Metodologi Penelitian}

Jenis penelitian kuantitatif dengan observasional analitik menggunakan pendekatan prospektif, teknik pengambilan sampel menggunakan accidental sampling sebanyak 25 responden sesuai dengan kriteria inklusi dan eksklusi. Penelitian dilakukan pada bulan November-Desember 2019. Kriteria inklusi meliputi bayi yang menjalani rawat inap di ruang perina RSUD Banyumas, mengalami asfiksia dengan nilai apgar menit pertama maximal 6, berumur kurang dari 28 hari, dan mendapatkan terapi oksigen selama 24 jam melalui bantuan alat pernapasan (nasal, head box, CPAP, atau Synchroized Intermittent Mandatory Ventilation) dan orang tua bersedia menjadi responden dengan menandatangi informed consent. Untuk kriteria eksklusi adalah bayi yang mengalami sepsis, kelainan kongenital jantung, dan bayi dengan 
Faletehan Health Journal, 8 (1) (2021) 65-70 www. journal.Ippm-stikesfa.ac.id/ojs/index.php/FHJ ISSN 2088-673X | 2597-8667

hernia diafragma. Pengambilan data dilakukan sesaat bayi setelah lahir untuk menentukan derajat asfiksia, kemudian dilakukan pengukuran nilai Downes score, selanjutnya diberikan terapi oksigen sesuai kebutuhan setelah $1 \times 24$ jam dilakukan pengukuran nilai Downes score kembali untuk memastikan keefektifan terapi. Analisis data menggunakan uji Wilcoxon test.

Untuk menjamin kemanan dan keselamatan responden peneliti melalui serangkaian proses perijinan dan presentasi proposal termasuk penyediaan informed consent, Standar Operational Procedure (SOP) dan tindakan penanganan. Penelitian ini telah mendapatkan ijin dari rumah sakit dan persetujuan etik dengan Nomor: 049/KEPK-RSUDBMS/XI/2019.

\section{Hasil dan Pembahasan}

\section{Karakteristik Responden}

Data karakteristik responden yang terdiri berat badan, panjang, masa gestasi dan umur ibu disajikan dalam tabel 1 berikut:

Tabel 1. Karakteristik Responden Pasien Asfiksia Neonatus $(n=25)$

\begin{tabular}{lcc}
\hline \multicolumn{1}{c}{ Variabel } & \multicolumn{1}{c}{ Mean \pm SD } & Min-Max \\
\hline Berat Badan Bayi & $2683,96 \pm 869,007$ & $\begin{array}{l}1090- \\
3770\end{array}$ \\
& & $36-54$ \\
\hline Panjang Bayi & $47,20 \pm 5,148$ & $27-42$ \\
\hline Masa Gestasi & $36,44 \pm 4,900$ & $19-38$ \\
\hline Umur Ibu & $29,12 \pm 6,051$ & \\
\hline
\end{tabular}

Tabel 1 menunjukkan rata-rata berat badan bayi 2683,96 gram. Masa gestasi 35,96 minggu, rata-rata umur ibu adalah 29,12 tahun. Rata-rata usia kehamilan ibu adalah pada kelahiran prematur, bayi ini akan mengalami immaturitas paru, dimana paru-paru bayi belum cukup untuk berkembang dengan penuh karena kurangnya zat surfaktan. Surfaktan membantu paru-paru mengembangkan udara dan melindungi kantong udara dari kolap paru sehingga terjadi kegawatan nafas neonatus (Marfuah et al., 2013). Bayi prematur sering mengalami gangguan pernafasan dikarenakan kekurangan surfaktan, pertumbuhan dan perkembangan paru yang belum sempurna, otot pernafasan yang masih lemah, dan tulang iga yang mudah melengkung (Prawirohardjo, 2016). Menurut Prawirohardjo (2016) umur ibu tidak secara langsung mempengaruhi terhadap kejadian asfiksia pada bayi baru lahir, hanya berpengaruh pada proses reproduksi dan faktor predisposisi untuk terjadinya pre eklamsia, seperti dalam penelitian ini sebanyak $88 \%$ ibu tidak memiliki penyakit penyerta.

Berdasarkan table 2 didapatkan data bahwa Sebagian besar jenis kelamin bayi adalah laki laki (56\%) dengan riwayat ibu tanpa penyakit (88\%), apgar skor sedang (88\%) dengan kelahiran spontan (64\%), Berat badan lahir cukup (BBLC), asfiksia (64\%), dan sebagian besar paritas ke 1 (40\%) dan 2(44\%). Paritas merupakan faktor penting dalam menentukan nasib ibu dan janin baik selama kehamilan maupun selama proses persalinan. Berdasar tinjauan literatur paritas 1 lebih banyak mengalami asfiksia. Hasil ini selaras dengan penelitian (Nilasari et al., 2019) yang menyebutkan bahwa terdapat hubungan yang positif dan secara statistik signifikan antara paritas dengan resiko untuk melahirkan bayi dengan asfiksia. Sebayak 14 responden (56\%) merupakan bayi laki-laki yang mengalami asfiksia neonatorum. Senada dengan penelitian (Marfuah et al., 2013) ada 55,8\% bayi berjenis kelamin laki-laki yang mengalami gawat nafas, walaupun jenis kelamin tidak berpengaruh besar terhadap asfiksia. Sebanyak 16 responden (64\%) dengan diagnosis BBLC asfiksia, kondisi ini didapat bisa karena proses persalian, faktor bayi juga faktor ibu, dari 16 BBLC dengan asfiksia tersebut 8 bayi $(50 \%)$ lahir spontan dan $50 \%$ lainnya lahir dengan caesar.

Hasil penelitian menunjukan dari 25 responden sebanyak 22 (22\%) bayi mengalami asfiksia sedang dengan nilai apgar 5 menit pertama mulai dari angka 6-4, sisanya 3 responden dengan asfiksia berat. Sedangkan 22 responden dengan asfiksia sedang dengan Downes score ringan sebanyak 19 responden dan 3 responden dengan Downes score sedang. Sementara 3 responden afiksia berat 2 responden dengan Downes score berat. Hanya 1 asfiskia berat dengan Downes score sedang.

\section{Efektifitas terapi oksigen terhadap Downes score pada pasien asfiksia neonates}

Berdasarkan tabel 3 didapatkan nilai rata-rata Downes score responden sebelum terapi oksigen sebesar 3,20 2 ,041dan sesudah terapi oksigen nilai rata-rata berubah menjadi $1,04 \pm 1,881$. Hasil analisis bivariat dengan menggunakan uji Wilcoxon, diperoleh nilai $\mathrm{Z}$ sebesar $-4,173$ dan nilai significancy sebesar $0,001(\mathrm{p}<0,05)$, sehingga dapat disimpulkan terdapat efektifitas terapi oksigen terhadap Downes Score pada pasien asfiksia neonatus Di Ruang Perina Rumah Sakit 
Banyumas (Tabel 3). Hasil penelitian ini menunjukan Downes score nilainya menurun ketika dilakukan terapi oksigen pada bayi asfiksia setelah 1x24 jam.

Hasil penelitian menunjukkan sebanyak 23 responden (93\%) mengalami penurunan pada Downes score yang artinya kondisi kagawatan nafas membaik. Tetapi ada 2 responden (8\%) mengalami kenaikan Downes score atau kondisi pernafasan menurun. Dua responden yang mengalami perburukan kodisi kegawatan nafas ini sama-sama dengan diagnosis hipoglikemia, namun persentase hipoglikemia ini kecil pada bayi yang mengalami asfiksia (Razaz et al., 2019). Responden pertama dengan penyulit perdarahan antepartum lahir secara Caesar umur gestasi 37 minggu dengan nilai apgar sedang, bayi didiagnosis Hypoksia Ischemic Encephalopathy (HIE) juga mengalami hipoglikemia, Downes score pra terapi oksigen 5 dan Downes score pasca terapi oksigen 6.

Tabel 2. Distribusi frekuensi jenis kelamin bayi, penyakit ibu, apgar score, cara lahir dan alat bantu Pasien Asfiksia Neonatus ( $\mathrm{n}=25)$

\begin{tabular}{|c|c|c|}
\hline Variabel & Frekuensi & Persentase \\
\hline \multicolumn{3}{|l|}{ Jenis Kelamin Bayi } \\
\hline Laki-laki & 14 & $56 \%$ \\
\hline Perempuan & 11 & $44 \%$ \\
\hline \multicolumn{3}{|l|}{ Penyakit Ibu } \\
\hline Nefrotik Sindrom & 1 & $4 \%$ \\
\hline Preeklamsi Berat & 1 & $4 \%$ \\
\hline Perdarahan & 1 & $4 \%$ \\
\hline Tidak ada & 22 & $88 \%$ \\
\hline \multicolumn{3}{|l|}{ Paritas } \\
\hline Ke 1 & 10 & $4 \%$ \\
\hline Ke 2 & 11 & $44 \%$ \\
\hline Ke 3 & 4 & $16 \%$ \\
\hline \multicolumn{3}{|l|}{ Apgar Score } \\
\hline Sedang & 22 & $88 \%$ \\
\hline Berat & 3 & $12 \%$ \\
\hline \multicolumn{3}{|l|}{ Cara Lahir } \\
\hline Caesar & 8 & $32 \%$ \\
\hline Spontan & 16 & $64 \%$ \\
\hline Vakum & 1 & $4 \%$ \\
\hline \multicolumn{3}{|l|}{ Alat Bantu Pernafasan } \\
\hline Nasal & 16 & $64 \%$ \\
\hline Nasal CPAP & 2 & $8 \%$ \\
\hline Nasal SIMV & 1 & $4 \%$ \\
\hline Non invasive Ventilation $C P A P$ & 1 & $4 \%$ \\
\hline Non invasive Ventilation SIMV & 2 & $8 \%$ \\
\hline Pressure Control SIMV & 3 & $12 \%$ \\
\hline \multicolumn{3}{|l|}{ Diagnosis Bayi } \\
\hline Berat Badan Lahir Cukup (BBLC) Asfiksia & 16 & $64 \%$ \\
\hline Berat Badan Lahir Rendah (BBLR) Asfiksia & 4 & $16 \%$ \\
\hline Berat Badan Lahir Sangat Rendah (BBLSR) Asfiksia & 3 & $12 \%$ \\
\hline $\begin{array}{l}\text { BBLC, Hypoksia Ischemic Encephalopathy (HIE), } \\
\text { Hipoglikemi }\end{array}$ & 1 & $4 \%$ \\
\hline BBLR, Hyaline Membrane Disease (HMD) Hipoglikemi & 1 & $4 \%$ \\
\hline
\end{tabular}

Tabel 3. Efektifitas terapi oksigen terhadap Downes score pada pasien asfiksia n (25)

\begin{tabular}{lccccc}
\hline & n & Median (min-maks) & Mean \pm S.D & Nilai Z & $\boldsymbol{p}$ \\
\hline Downes score pra terapi oksigen & 25 & $3(1-9)$ & $3,20 \pm 2,041$ & \multirow{2}{*}{$-4,173$} & \multirow{2}{*}{0,001} \\
Downes score pasca terapi oksigen & 25 & $0(0-7)$ & $1,04 \pm 1,881$ & & \\
\hline
\end{tabular}


Faletehan Health Journal, 8 (1) (2021) 65-70

Hipoglikemia pada bayi merupakan kondisi gula darah $<50 \mathrm{mg} / \mathrm{dl}$ jika kondisi hipoglikemi yang berlanjut dapat merusak otak karena reaksi ketogenik yaitu metabolisme dari asam lemak menjadi keton, maka otak akan memanfaatkan keton untuk menghemat glukosa (Mirtha et al., 2016). HIE merupakan kondisi sindrom klinis dengan gangguan neurologi pada awal kehidupan neonatus dengan usia kemahilan pada atau lebih dari 35 minggu, dapat dipicu dari kondisi asfiksia (Anggriawan, 2016).

Kenaikan nilai Downes score juga dialami responden satunya dengan diagnosa BBLR Asfiksia, hipoglikemi dan Hyaline Membrane Disease (HMD). Penyakit membrane hialin paling banyak dialami oleh bayi premature salah satu penyebabnya adalah asfiksia serta dapat mengakibatkan kematian bayi sebesar OR 4,97 (IK 95\% 2,39-10,28). Berkumpulnya beberapa diagnosis pada neonatus tentunya dapat menurunkan kondisi, sehingga hal tersebut mempengaruhi responden yang ikut meningkat derajat kegawatan pernafasannya ditandai meningkatnya Downes score, serta komplikasi terkait asfiksia dan hipoglikemia. Sebanyak $88 \%$ responden yang mengalami asfiksia sedang sisanya $22 \%$ dengan asfiksia berat. Setelah pemberian terapi oksigen dan diukur dengan menggunakan Downes score selama $1 \times 24$ jam kondisi derajat asfiksia 23 bayi menurun, namun ada 2 responden memburuk.

Penggunaan terapi oksigen yang berbeda-eda hal ini karena pemberian oksigen dilihat dari nilai Downes score, semakin tinggi nilainya maka alat bantu nafas yang digunakan membutuhkan tekanan yang tingi. Hal ini sesuai dengan teori, bahwa pemberian terapi oksigen tergantung pada penyebab dan jenis atau derajat gangguan nafas tersebut dimana manajemen spesifik dalam penatalaksanaan pemenuhan kebutuhan oksigen pada bayi dengan gangguan nafas berat dianjurkan dengan pemberian $\mathrm{O} 2$ dengan kecepatan aliran sedang yaitu antara rendah $<6$ liter/menit dan tinggi $>15$ liter/menit (Kosim, 2016).

Sejalan dengan penelitian Marfuah et al., (2013) bayi dengan AS < 7 dengan terjadinya RDS mempunyai nilai $\mathrm{p}<0,001$ artinya ada hubungan bermakna. Alat bantu nafas yang digunakan pada bayi asfiksia, dari 25 responden sebanyak 16 (64\%) menggunakan alat bantu nasal kanul dengan kondisi asfiksia sedang dan tingkat Downes score ringan sebelum terapi oksigen yaitu nilai antara 1 3, dan nilai Downes score setelah terapi oksigen adalah 0 , yang artinya mengalami perbaikan dengan menurunnya nilai Downes score sekaligus memperbaiki derajat asfiksia. Manjemen Downes score ringan dapat menggunakan oksigen nasal atau CPAP, untuk Downes score sedang terapi oksigen yang digunakan mulai dari CPAP hingga SIMV, sedangkan untuk Downes score berat oksigen yang digunakan adalah PC SIMV. Pada distress nafas untuk masa gestasi < 30 minggu diberikan terapi oksigen dengan CPAP bila gagal maka dilanjutkan dengan NIV SIMV (Mirtha et al., 2016).

Tujuan manajemen penatalaksanaan kegawatan nafas (respiratory distress) adalah untuk memberikan intervensi yang memaksimalkan kelangsungan hidup dan meminimalkan potensial komplikasi dan mengurangi paparan penggunaan mekanik metode invasif (Kosim, 2016; Sweet et al., 2017). Hal ini dapat menjadi acuan dalam penanganan bayi asfiksia dimana penurunan nilai Downes score sebanyak $93 \%$ atau tercapainya penanganan bayi asfiksia dengan pemberian terapi oksigen, sejalan dengan perlindungan terhadap paru-paru penting dalam salah satu manajeman gangguan respirasi (Sweet et al., 2019).

\section{Simpulan}

Terapi oksigen efektif dalam menurunkan Downes score pada pasien asfiksia neonates, Downes score merupakan alat ukur kegawatan nafas pada neonatus cepat dan cukup sederhana, sekaligus sebagai acuan menentukan jenis terapi oksigen yang hendak digunakan. Downes Score dapat digunakan dirumah sakit utuk mengukur keefektifan terapi oksigen.

\section{Referensi}

Anggraini, A., Sumadiono, S., \& Wandita, S. (2016). Faktor Risiko Kematian Neonatus dengan Penyakit Membran Hialin. Sari Pediatri.

https://doi.org/10.14238/sp15.2.2013.75-80

Anggriawan, A. (2016). Tinjauan Klinis HypoxicIschemic Encephalopathy. Cdk-243.

Brahmaiah, P., \& Reddy, K. R. (2017). Etiological Study of Respiratory Distress in Newborn. International Journal of Contemporary Medical Research, 4(10), 2202-2206. 
https://www.ijcmr.com/uploads/7/7/4/6/7746 4738/ijcmr 1736 v2.pdf

Buch, P. M., Makwana, A. M., \& Chudasama, R. K. (2013). Usefulness of Downe Score as clinical assessment tool and Bubble CPAP as primary respiratory support in neonatal respiratory distress syndrome. Journal of Pediatric https://doi.org/10.17334/jps.55282

Sciences.

Harada, E., Kinoshita, M., Iwata, S., Saikusa, M., Tsuda, K., Shindou, R., Sahashi, T., Kato, S., Yamada, Y., Saitoh, S., \& Iwata, O. (2019). Visual function scale for identification of infants with low respiratory compliance. Pediatrics and Neonatology. https://doi.org/10.1016/j.pedneo.2019.02.006

Hedstrom, A. B., Gove, N. E., Mayock, D. E., \& Batra, M. (2018). Performance of the Silverman Andersen Respiratory Severity Score in predicting $\mathrm{PCO} 2$ and respiratory support in newborns: A prospective cohort study. Journal of Perinatology. https://doi.org/10.1038/s41372-018-0049-3

Indriani, N., Rustina, Y., \& Agustini, N. (2015). Perkembangan Bayi Usia 6-12 Bulan dengan Riwayat Asfiksia Perinatal. Jurnal Keperawatan Indonesia. https://doi.org/10.7454/jki.v18i2.414

John, B. M., Venkateshwar, V., \& Dagar, V. (2015). Predictors of outcome in neonates with respiratory distress. Journal of Nepal Paediatric Society. https://doi.org/10.3126/jnps.v35i1.11868

Kosim, M. S. (2016). Gawat Darurat Neonatus pada Persalinan Preterm. Sari Pediatri. https://doi.org/10.14238/sp7.4.2006.225-31

Marfuah, M., Barlianto, W., \& Susmarini, D. (2013). FAKTOR Risiko Kegawatan Nafas Pada Neonatus Di Rsd. Dr. Haryoto Kabupaten Lumajang Tahun 2013. Jurnal Ilmu Keperawatan.

Mirtha, L., Soegiharto, B., Endyarni, B., Harmoniati, E., Soesanti, F., Gunardi, H., Soetomenggolo, H., Kaswandani, N., \& Susanti, N. (2016). Kiat membuat anak sehat, tinggi, dan cerdas. Gaya Hidup Aktif Sebagai Modal Optimalisasi Kesehatan, Tumbuh Kembang, Dan Kecerdasan Anak, 27-28.

Mochtar, R. (2013). Sinopsis Obstetri: Obstetri Fisiologi. In EGC.

Nilasari, N., Kharisma, B., \& Puti, A. (2019). Analisis Faktor Penyebab Kejadian Asfiksia pada Bayi Baru Lahir. Jurnal Ners Dan Kebidanan.

Pattar, M., \& Das, L. (2018). A Comparative Study Of Surfactant Versus Nonsurfactant Therapy Among Preterm With Respiratory Distress Syndrome. Indian Journal of Child Health. https://doi.org/10.32677/ijch.2018.v05.i07.00 5

Prawirohardjo, S. (2016). Ilmu Kebidanan Sarwono Prawirohardjo. Edisi Ke-4. Jakarta: Yayasan Bina Pustaka Sarwono Prawirohardjo.

Profil Kesehatan Indonesia. (2016). Profil Kesehatan RI 2015. In Profil Kesehatan Indonesia Tahun 2015.

Razaz, N., Cnattingius, S., \& Joseph, K. S. (2019). Association between Apgar scores of 7 to 9 and neonatal mortality and morbidity: Population based cohort study of term infants in Sweden. The BMJ. https://doi.org/10.1136/bmj.11656

Sashidhar, A., Suman Rao, PN. \& Jose, J. (2016). Downes Score vs Silverman Anderson Score for Assessment of Respiratory Distress in Preterm Newborns. Pediatric Oncall. https://doi.

. P., Vento, M., Visser, G. H. A., \& Halliday, H. L. (2017). European Consensus Guidelines on the Management of Respiratory Distress Syndrome org/10.7199/ped.oncall.2016.30

Sweet, D. G., Carnielli, V., Greisen, G., Hallman, M., Ozek, E., Plavka, R., Saugstad, O. D., Simeoni, U., Speer, C - 2016 Update. Neonatology. https://doi.org/10.1159/000448985

Sweet, D. G., Carnielli, V., Greisen, G., Hallman, M., Ozek, E., Te Pas, A., Plavka, R., Roehr, C. C., Saugstad, O. D., Simeoni, U., Speer, C. P., Vento, M., Visser, G. H. A., \& Halliday, H. L. (2019). European Consensus Guidelines on the Management of Respiratory Distress Syndrome - 2019 Update. In Neonatology. https://doi.org/10.1159/000499361 